ARTICLE

Received 21 Jan 2014 | Accepted 23 Jun 2014 | Published 24 Jul 2014

\title{
Diastereodivergent organocatalytic asymmetric vinylogous Michael reactions
}

Xin $\mathrm{Li}^{1}$, Min $\mathrm{Lu}^{1}$, Yun Dong ${ }^{1}$, Wenbin Wu${ }^{1}$, Qingqing Qian ${ }^{1}$, Jinxing $\mathrm{Ye}^{1} \&$ Darren J. Dixon ${ }^{2}$

One of the major challenges of modern asymmetric catalysis is the ability to selectively control the formation of all diastereoisomers of reaction products possessing multiple stereocenters. Pioneers of such diastereodivergent catalytic asymmetric processes have focused on reactions where the newly formed stereogenic centres are proximal to the active carbonyl group. To date, however, diastereodivergent reactions at remote positions remain an unmet challenge. Herein, we describe a catalyst-controlled diastereodivergence in the formation of remote stereocenters in the direct vinylogous Michael reactions of $\beta$, $\gamma$-unsaturated butenolides to $\alpha, \beta$-unsaturated ketones. The reactions are enabled by two complementary, non-enantiomeric multifunctional catalysts, which mutually activate and organise both reactants, affording either the syn- or anti-adduct with high diastereo- and enantioselectivity. These two catalytic systems are also applicable in the Mukaiyama-Michael reactions and tandem Michael-Michael reactions.

\footnotetext{
${ }^{1}$ Shanghai Key Laboratory of New Drug Design, School of Pharmacy, East China University of Science and Technology, 130 Meilong Road, Shanghai 200237 , China. ${ }^{2}$ Department of Chemistry, Chemistry Research Laboratory, University of Oxford, Mansfield Road, Oxford OX1 3TA, UK. Correspondence and requests for materials should be addressed to J.Y. (email: yejx@ecust.edu.cn) or to D.J.D. (email: darren.dixon@chem.ox.ac.uk).
} 
W ith the continual advancement of catalytic asymmetric synthesis over the last few decades, increasing numbers of highly diastereo- and enantio-selective reactions affording stereochemically defined products possessing multiple stereocenters have been reported. Commonly, through inherent substrate control, one of the possible diastereomeric products predominates the reaction mixture ${ }^{1}$, and naturally, the absolute stereochemical outcome can be controlled by choice over which enantiomeric form of catalyst is employed. However, overriding natural substrate diastereoselectivity to bias the formation of the other diastereoisomers still remains a significant challenge ${ }^{2}$.

Catalyst-controlled diastereodivergence would be highly desirable to solve this shortcoming and such asymmetric processes could significantly advance the field ${ }^{3}$. Researchers including MacMillan $^{4}$, Deng ${ }^{5,6}$, Melchiorre ${ }^{7}$, Maulide ${ }^{8,9}$, Carreira ${ }^{10,11}$ have pioneered diastereodivergent asymmetric catalysis and realized the asymmetric functionalization of $\alpha$ - or $\beta$-positions (relative to the active carbonyl group). Controlling the selective formation of remote stereocenters remains a difficult synthetic goal, which has attracted significant attention and resulted in ingenious solutions ${ }^{12}$. However, to date, the application of diastereodivergent catalytic asymmetric strategies to control the selective formation of remote stereocenters in carbon-carbon bond-forming reactions (such as vinylogous Michael reaction) remains elusive.

Initially, we wanted to focus our attention on the enantioselective synthesis of $\gamma, \gamma$-disubstituted butenolides from prochiral precursors such as deconjugated butenolides. These compounds contain quaternary stereogenic centres and are important motifs in biologically active natural compounds and medicinally important agents ${ }^{13-18}$. The organocatalytic asymmetric synthesis of $\gamma, \gamma$-disubstituted butenolide derivatives has attracted much attention in the past few years ${ }^{19-26}$. However, the key limitation encountered with the previous asymmetric vinylogous reactions using $\beta, \gamma$-butenolides was that only one diastereoisomer was accessed, therefore making it relevant to this study.

Herein, we present our development of the first example of a highly diastereodivergent, asymmetric and direct vinylogous Michael reactions of $\beta, \gamma$-unsaturated butenolides to $\alpha$, $\beta$-unsaturated ketones, generating both anti- and syn-adducts by employing complementary, non-enantiomeric primary amine catalytic systems.

\section{Results}

The catalytic mechanism. In an ongoing research programme, we have focused on the development of new primary amine catalysts and their application in asymmetric conjugate addition reactions of various pro-nucleophiles to $\alpha, \beta$-unsaturated ketone $^{27-30}$. We envisaged that variations in the backbones, substituents, connectivity and the presence of additional functionality in different primary amine catalysts could give rise to sufficient differences in the local spatial environment to impact on both diastereo- and enantiocontrol. Particularly, we believed adjusting the nature and size of those groups (such as tertiary amine or secondary amine, hydrogen bond donor) flanking the key primary amine functional group could permit two types of noncovalent interactions: weak and loose, or strong and tight hydrogen-bonding interaction between the catalyst and reactant. A weak and loose $\mathrm{H}$-bonding interaction can direct one of the reactants, while the steric hindrance between two reactants dominates the stereoselectivity. A strong and tight H-bonding interaction can preferentially control the position and orientation of the reactive nucleophilic entity, lower the energy barrier coming from steric hindrance of two reactants and produce the diasteromer which is normally inaccessible. From this, the stereoselective discrimination of the reaction partners and anticipant modulation of the diastereo- and enantioselectivity of the Michael reaction could be realized (Fig. 1). Our aim was to develop two complementary, non-enantiomeric, multifunctional primary amine catalytic systems possessing different skeletal constructs to obtain anti- or syn-products in high enantio- and diastereoselectivities across a range of reaction types.

Optimization of anti-selective Michael reaction conditions. To probe the feasibility of catalyst-controlled diastereodivergence in the direct Michael addition of $\beta, \gamma$-unsaturated butenolides and $\alpha$, $\beta$-unsaturated ketones, we investigated as a model reaction the addition of $\gamma$-phenyl-butenolide $2 \mathbf{a}$ and 3-hepten-2-one 1a employing a range of primary amine catalysts (at $10 \mathrm{~mol} \%$ loading) in the presence of $20 \mathrm{~mol} \%$ of benzoic acid. First, we investigated a series of chiral primary amine catalysts (Table 1). The observed anti/syn-selectivities employing three common primary amine catalysts 5, 6 and $\mathbf{7}$ (entries 1-3) ranged from 25/ 75 to $58 / 42$, hence providing proof of concept. Subsequently, two diamines derived from $L$-tert-leucine (catalysts 8 and 9) were screened. The best result of diastereomeric ratio (d.r.) (84/16, entry 4) suggested that a primary amine possessing a vicinal secondary amine permitting strong and tight $\mathrm{H}$-bonding interaction with $\beta, \gamma$-unsaturated butenolides (for example, catalyst 8) might be a suitable catalyst construct for anti-selectivity. Then, catalysts 10a-d with the same scaffold of a primary amine, a vicinal secondary amine and sulphonamide as a terminal hydrogen bond donor were tested (entries 6-9). We hoped that the three functional groups could generate the spatially defined chiral pocket necessary to govern both diastereo- and enantiocontrol. Fortunately and very pleasingly, these experiments provided the anti-adduct in excellent enantioselectivities (97-99\% enantiomeric excess (e.e.)) with d.r. up to 91/9. The diastereoselectivity of the reaction was observed to be greatly dependent on the steric hindrance around the primary amine group. Certain parameters were adjusted and optimised (Supplementary
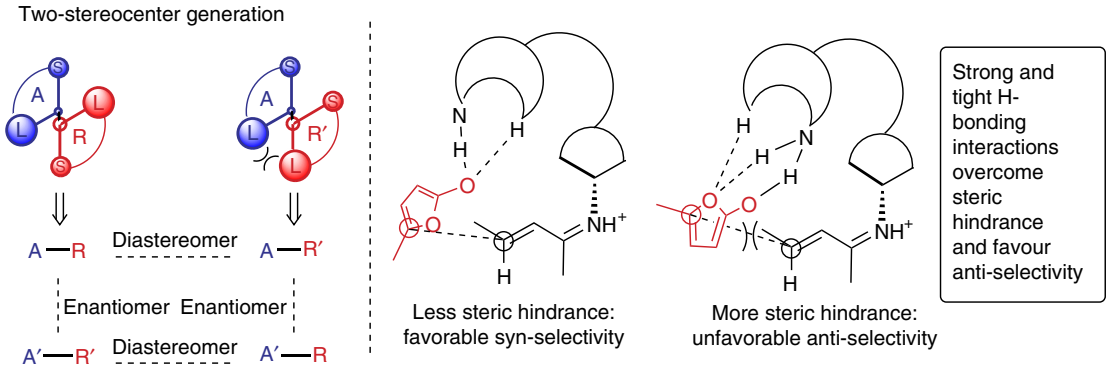

Figure 1 | The catalytic mechanism. The designed concepts for the diastereodivergent catalytic asymmetric vinylogous Michael reactions with multifunctional catalysts. 
Table 1 | Screening studies of anti-selective Michael reactions of 1a and $2 a$.

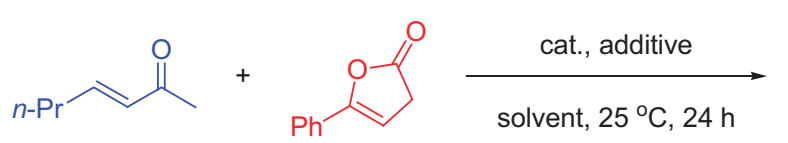

$1 \mathrm{a}$

$0.1 \mathrm{mmol}$

\section{2a}

1.5 equiv<smiles>CC(=O)CC(CC(C)C)C1(c2ccccc2)CC(=O)CO1</smiles>

$(R, R)-3$ aa major diastereoisomer

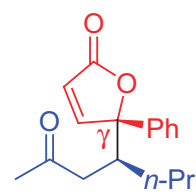

$(R, S)-4 a a$

minor

diastereoisomer

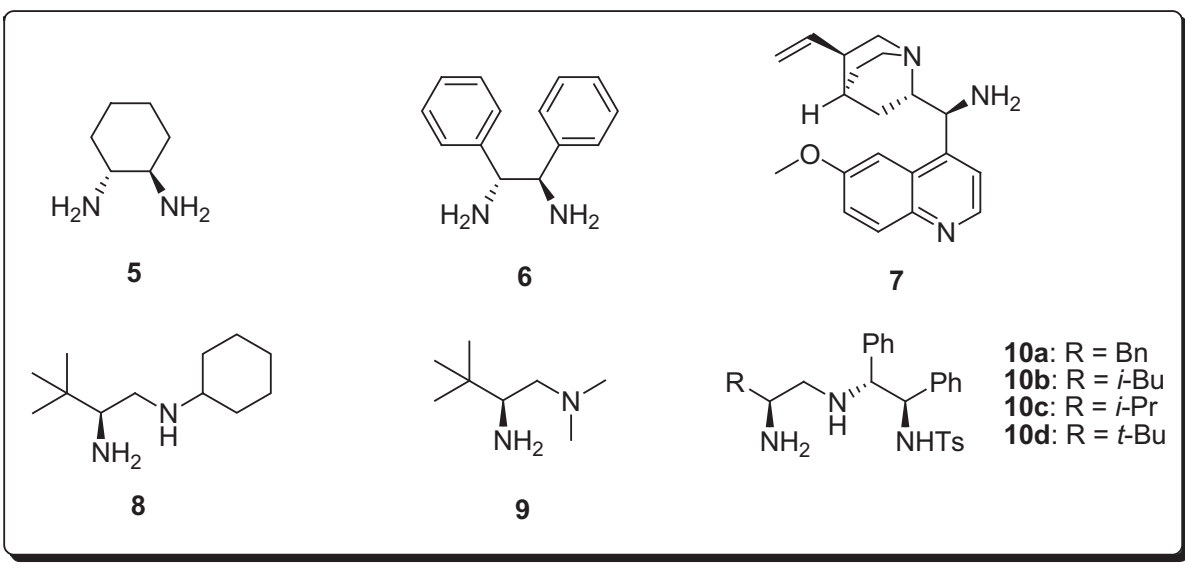

\begin{tabular}{|c|c|c|c|c|c|}
\hline Entry $^{\star}$ & Catalyst & Acid & Conversion ${ }^{\dagger}(\%)$ & $\begin{array}{c}\text { Diastereomeric } \\
\text { ratio (d.r.) }{ }^{\ddagger} \text { anti/syn }\end{array}$ & $\begin{array}{c}\text { Enantiomeric } \\
\text { excess (e.e.) })^{\S}(\%)\end{array}$ \\
\hline 1 & 5 & $\mathrm{C}_{6} \mathrm{H}_{5} \mathrm{CO}_{2} \mathrm{H}$ & 73 & $25 / 75$ & $-74 / 75$ \\
\hline 2 & 6 & $\mathrm{C}_{6} \mathrm{H}_{5} \mathrm{CO}_{2} \mathrm{H}$ & 76 & $28 / 72$ & $-92 / 63$ \\
\hline 3 & 7 & $\mathrm{C}_{6} \mathrm{H}_{5} \mathrm{CO}_{2} \mathrm{H}$ & 13 & $58 / 42$ & $98 /-32$ \\
\hline 4 & 8 & $\mathrm{C}_{6} \mathrm{H}_{5} \mathrm{CO}_{2} \mathrm{H}$ & 65 & $84 / 16$ & $84 /-22$ \\
\hline 5 & 9 & $\mathrm{C}_{6} \mathrm{H}_{5} \mathrm{CO}_{2} \mathrm{H}$ & 29 & 8/92 & $98 /-52$ \\
\hline 6 & $10 a$ & $\mathrm{C}_{6} \mathrm{H}_{5} \mathrm{CO}_{2} \mathrm{H}$ & 53 & $71 / 29$ & $>99 /-57$ \\
\hline 7 & $10 b$ & $\mathrm{C}_{6} \mathrm{H}_{5} \mathrm{CO}_{2} \mathrm{H}$ & 41 & $64 / 36$ & $97 /-57$ \\
\hline 8 & $10 c$ & $\mathrm{C}_{6} \mathrm{H}_{5} \mathrm{CO}_{2} \mathrm{H}$ & 61 & $81 / 19$ & $>99 /-57$ \\
\hline 9 & 10d & $\mathrm{C}_{6} \mathrm{H}_{5} \mathrm{CO}_{2} \mathrm{H}$ & 64 & $91 / 9$ & 98/N.D. \\
\hline $10^{11}$ & 10d & $\mathrm{o}-\mathrm{NO}_{2}-\mathrm{C}_{6} \mathrm{H}_{4} \mathrm{CO}_{2} \mathrm{H}$ & 71 & $97 / 3$ & 99/N.D. \\
\hline
\end{tabular}

N.D., not detected.

${ }^{*}$ Reaction conditions: 1a $(0.10 \mathrm{mmol}, 1.0$ equiv. $), 2 a(0.15 \mathrm{mmol}, 1.5$ equiv. $)$, catalyst ( 0.1 equiv.) and acid $(0.2$ equiv. $)$ in $\mathrm{CH}_{2} \mathrm{Cl}_{2}(\mathrm{C}=0.5 \mathrm{M})$ at $25^{\circ} \mathrm{C}$ for $24 \mathrm{~h}$.

$\dagger$ Determined by gas chromatography analysis.

†ेDetermined by gas chromatography analysis.

Determined by chiral high-performance liquid chromatography analysis.

IIThe reaction was carried out in $\mathrm{CHCl}_{3}(\mathrm{C}=0.5 \mathrm{M})$.

Table 1), including the change of the solvent (from $\mathrm{CH}_{2} \mathrm{Cl}_{2}$ to $\mathrm{CHCl}_{3}$ ) and acidic additives (from benzoic acid to 2-nitrobenzoic acid), to achieve $71 \%$ conversion after $24 \mathrm{~h}$ reaction time, 97/3 d.r. and $99 \%$ e.e. (entry 10 ).

Optimization of syn-selective Michael reaction conditions. After optimization of the conditions for anti-selectivity, the approach for obtaining the other syn-diastereoisomer was further investigated (Table 2). In our initial study, we noted a significant enantioselectivity and reversed diastereoselectivity when catalysts 5 and 6 were employed (Table 1, entries 1 and 2). The role of one of the primary amine groups of catalyst $\mathbf{5}$ and $\mathbf{6}$ is to activate the enone through generation of an iminium intermediate. It is likely that the other primary amine controls the direction of the nucleophile's attack by hydrogen-bonding interactions. Accordingly, catalysts derived from diamines $\mathbf{5}$ and $\mathbf{6}$ with enhanced hydrogen bond donation ability were conceived to enhance performance.

Bifunctional primary amine-thiourea catalysts 11, 12, 13 and 14 were applied to the model reaction without acidic additives.
Good diastereoselectivities (28/72 to 6/94 d.r.) and enantioselectivities (up to $89 \%$ e.e.) were obtained (entries 1-4, Table 2). Reactivity, as indicated by conversion after $24 \mathrm{~h}$, was disappointing in entries 5-6 when $10 \mathrm{~mol} \%$ of catalyst 14 and $10 \mathrm{~mol} \%$ or $20 \mathrm{~mol} \%$ of benzoic acid was employed as the catalytic system; however, enantioselectivity was marginally improved. After altering a number of the reaction parameters (Supplementary Table 2), including the acid co-catalyst (from benzoic acid to 2-fluorobenzoic acid, entry 7), extending the reaction time (from $24 \mathrm{~h}$ to $72 \mathrm{~h}$ ) and increasing the catalyst and acid additive loading (20 mol\%, entry 8 ), an ideal result of $82 \%$ conversion, $6 / 94$ d.r. and $97 \%$ e.e. was finally achieved.

Substrate scope of anti-selective Michael reaction. After the optimal reaction conditions were separately established, the scope of the reaction was investigated as shown in Table 3, using 10d as the optimal catalyst for anti-selectivity.

With (E)-hept-3-en-2-one as the Michael acceptor, a broad range of $\gamma$-substituted butenolides, bearing both alkyl substituents and electron-rich/deficient aryl substituents, were investigated. 
Table 2 | Screening studies of syn-selective Michael reactions of $1 \mathrm{a}$ and $2 \mathrm{a}$.
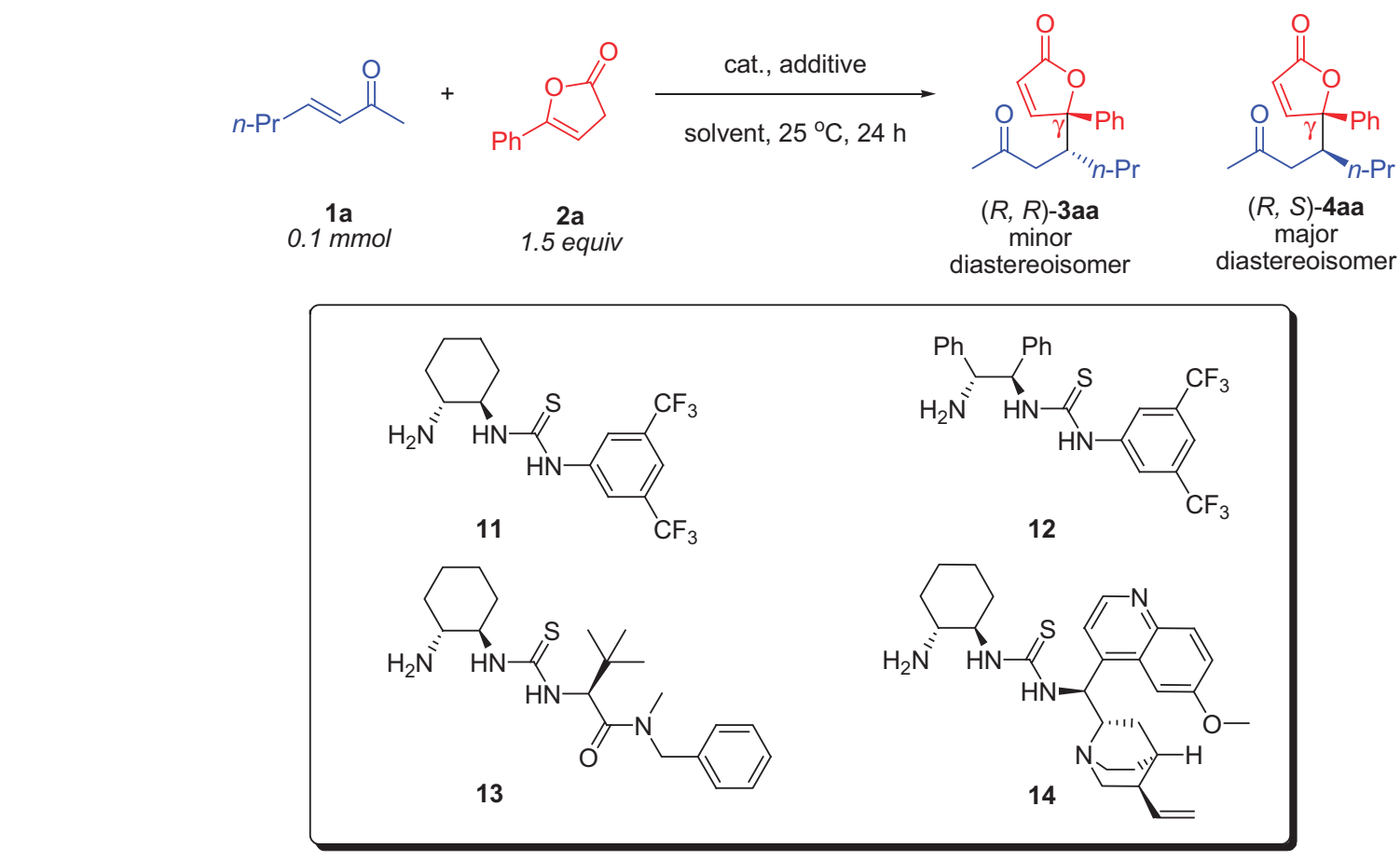

\begin{tabular}{|c|c|c|c|c|c|}
\hline Entry $^{\star}$ & Catalyst & Acid & Conversion $^{\dagger}$ (\%) & Diastereomeric ratio (d.r.) $\ddagger$ anti/syn & Enantiomeric excess (e.e.) ${ }^{\S}(\%)$ \\
\hline 1 & 11 & None & 13 & 7/93 & N.D./4 \\
\hline 2 & 12 & None & 16 & $6 / 94$ & N.D./29 \\
\hline 3 & 13 & None & 54 & $28 / 72$ & N.D./26 \\
\hline 4 & 14 & None & 23 & $8 / 92$ & N.D./89 \\
\hline 5 & 14 & $\mathrm{C}_{6} \mathrm{H}_{5} \mathrm{CO}_{2} \mathrm{H}$ & 18 & $9 / 91$ & N.D./90 \\
\hline $6^{11}$ & 14 & $\mathrm{C}_{6} \mathrm{H}_{5} \mathrm{CO}_{2} \mathrm{H}$ & 13 & $7 / 93$ & N.D./91 \\
\hline 7 & 14 & $\mathrm{o}-\mathrm{F}-\mathrm{C}_{6} \mathrm{H}_{4} \mathrm{CO}_{2} \mathrm{H}$ & 13 & $7 / 93$ & N.D./94 \\
\hline 8 & 14 & $\mathrm{o}-\mathrm{F}-\mathrm{C}_{6} \mathrm{H}_{4} \mathrm{CO}_{2} \mathrm{H}$ & 82 & $6 / 94$ & N.D./97 \\
\hline
\end{tabular}

The corresponding anti-products were obtained in good yields with excellent enantio- and diastereoselectivities (Table 3, entries 1-8). A butenolide with two alkyl substituents (Table 3, entry 9) gave slightly better enantioselectivities than a singly substituted one (Table 3, entry 6). Pleasingly, with 5-phenylfuran-2(3H)-one as the pro-nucleophile, a wide range of enone Michael acceptors bearing various alkyl substituents were reactive and found to give good yields, excellent enantio- and diastereoselectivities (Table 3, entries 10-17). Furthermore, other (random) combinations of different $\gamma$-substituted butenolides and enones also performed well (Table 3, entries 18-23). Reactions of a variety of $\gamma$-substituted butenolides and benzalacetone derivatives also proceeded smoothly giving uniformly excellent enantioselectivities, regardless of the position and electron-donating or electronwithdrawing nature of the substituent on the aromatic ring (Table 3, entries 24-32). However, with respect to the diastereoselectivity, the result varies with the type of substituent at the $\gamma$-position of the butenolides; those with alkyl groups (Table 3, entries 27-29, 31-32) performed relatively better than those with an aryl group (Table 3, entries 24-26, 30). As for cyclic Michael acceptors, excellent enantioselectivities were observed in moderate-to-good yields; however, 2-cyclopentenone gave a relatively poor diastereoselectivity compared with 2-cyclohexenone or 2-cycloheptenone (Table 3, entries 33-37). Taken altogether, our results demonstrate that catalyst 10d is broadly applicable in the anti-selective direct vinylogous Michael addition reaction.

Substrate scope of syn-selective Michael reaction. As indicated in Table 2, the syn-diastereoisomer can be obtained under the control of catalyst $\mathbf{1 4}$. To give a clear comparison with the antiselective reaction described above, the performance of catalyst $\mathbf{1 4}$ using exactly the same substrates as in Table 3 were investigated, and the results are summarized in Table 4.

With (E)-hept-3-en-2-one as the Michael acceptor, $\gamma$-substituted butenolides bearing electron-rich and -deficient aryl substituents, were investigated in this reaction. The corresponding syn-configured products were observed in moderate yields with good enantioselectivities and diastereoselectivities (from 1/ 11 to $<1 / 19$ d.r.) (Table 4 , entries $1-4$ ). Unexpectedly, results shown in entries 4-9 in Table 4 turned out to be disappointing under the optimized reaction conditions. After a simple screening of acidic additives (Supplementary Table 3), it was found that the 
Table 3 | Scope of the Michael reaction for the anti-diastereoisomers 3.

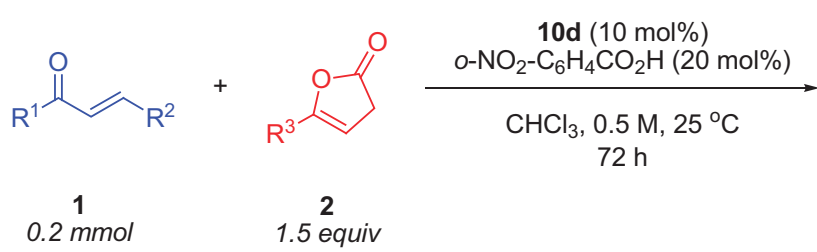<smiles>[R]C(=O)CC1C2=CC(=O)OC([R])(C1[R])C21CC1</smiles><smiles>[R]C(=O)CC1C=CC(=O)OC1([R])CC</smiles>

\begin{tabular}{|c|c|c|c|c|c|c|}
\hline Entry $^{\star}$ & $\mathbf{R}^{1}$ & $\mathbf{R}^{2}$ & $\mathbf{R}^{\mathbf{3}}$ & Yield (\%) ${ }^{\dagger}$ & $\begin{array}{l}\text { Diastereomeric } \\
\text { ratio (d.r.) }{ }^{\ddagger}\end{array}$ & $\begin{array}{c}\text { Enantiomeric } \\
\text { excess (e.e.) }(\%)^{\S}\end{array}$ \\
\hline 1 & $\mathrm{Me}$ & $n-\operatorname{Pr}$ & $\mathrm{C}_{6} \mathrm{H}_{5}$ & 95 (3aa) & $>19 / 1$ & 99 \\
\hline 2 & Me & $n-\operatorname{Pr}$ & $p-\mathrm{BrC}_{6} \mathrm{H}_{4}$ & $96(3 \mathbf{a b})$ & $>19 / 1$ & 99 \\
\hline 3 & Me & $n-\operatorname{Pr}$ & $p-\mathrm{MeC}_{6} \mathrm{H}_{4}$ & 94 (3ac) & $>19 / 1$ & 95 \\
\hline 4 & Me & $n-P r$ & $p-\mathrm{MeOC}_{6} \mathrm{H}_{4}$ & 76 (3ad) & $>19 / 1$ & 99 \\
\hline 5 & $\mathrm{Me}$ & $n-\operatorname{Pr}$ & $\mathrm{Me}$ & 86 (3ae) & $>19 / 1$ & 98 \\
\hline 6 & $\mathrm{Me}$ & $n-\operatorname{Pr}$ & Et & 81 (3af) & $>19 / 1$ & 97 \\
\hline 7 & $\mathrm{Me}$ & $n-\operatorname{Pr}$ & $n-\operatorname{Pr}$ & 82 (3ag) & $18 / 1$ & 97 \\
\hline 8 & Me & $n-P r$ & $\mathrm{Bn}$ & 72 (3ah) & $>19 / 1$ & 94 \\
\hline 9 & $\mathrm{Me}$ & $n-\operatorname{Pr}$ & & 73 (3ai) & $>19 / 1$ & $>99$ \\
\hline 10 & $\mathrm{Me}$ & $\mathrm{Me}$ & $\mathrm{C}_{6} \mathrm{H}_{5}$ & 69 (3aj) & $17 / 1$ & 98 \\
\hline 11 & $\mathrm{Me}$ & $n-B u$ & $\mathrm{C}_{6} \mathrm{H}_{5}$ & 84 (3ak) & $>19 / 1$ & 99 \\
\hline 12 & $\mathrm{Me}$ & n-amyl & $\mathrm{C}_{6} \mathrm{H}_{5}$ & 97 (3al) & $>19 / 1$ & 98 \\
\hline 13 & $\mathrm{Me}$ & n-hexyl & $\mathrm{C}_{6} \mathrm{H}_{5}$ & 99 (3am) & $>19 / 1$ & 98 \\
\hline 14 & Me & $i-\operatorname{Pr}$ & $\mathrm{C}_{6} \mathrm{H}_{5}$ & 86 (3an) & $>19 / 1$ & 97 \\
\hline 15 & $\mathrm{Me}$ & $i-B u$ & $\mathrm{C}_{6} \mathrm{H}_{5}$ & 80 (3ao) & $>19 / 1$ & 99 \\
\hline 16 & Me & $\left(\mathrm{CH}_{2}\right)_{2} \mathrm{C}_{6} \mathrm{H}_{5}$ & $\mathrm{C}_{6} \mathrm{H}_{5}$ & 80 (3ap) & $>19 / 1$ & 98 \\
\hline 17 & $\mathrm{Me}$ & $\mathrm{Bn}$ & $\mathrm{C}_{6} \mathrm{H}_{5}$ & 74 (3aq) & $>19 / 1$ & 98 \\
\hline 18 & $\mathrm{Me}$ & $\mathrm{Me}$ & $p-\mathrm{MeC}_{6} \mathrm{H}_{4}$ & 95 (3ar) & $>19 / 1$ & 98 \\
\hline 19 & $\mathrm{Me}$ & $n-B u$ & $\mathrm{Bn}$ & 86 (3as) & $>19 / 1$ & 97 \\
\hline 20 & $\mathrm{Me}$ & $i-\operatorname{Pr}$ & $p-\mathrm{MeC}_{6} \mathrm{H}_{4}$ & 92 (3at) & $>19 / 1$ & 98 \\
\hline 21 & $\mathrm{Me}$ & i-Bu & Et & 80 (3au) & $>19 / 1$ & 99 \\
\hline 22 & $\mathrm{Me}$ & n-amyl & $p-\mathrm{MeOC}_{6} \mathrm{H}_{4}$ & 82 (3av) & $>19 / 1$ & 99 \\
\hline 23 & Et & $\mathrm{Me}$ & $\mathrm{C}_{6} \mathrm{H}_{5}$ & 97 (3aw) & $19 / 1$ & $>99$ \\
\hline 24 & $\mathrm{Me}$ & $\mathrm{C}_{6} \mathrm{H}_{5}$ & $\mathrm{C}_{6} \mathrm{H}_{5}$ & 80 (3ax) & $6 / 1$ & 97 \\
\hline 25 & Me & $p-\mathrm{BrC}_{6} \mathrm{H}_{5}$ & $\mathrm{C}_{6} \mathrm{H}_{5}$ & 75 (3ay) & $5 / 1$ & 95 \\
\hline 26 & $\mathrm{Me}$ & $m-\mathrm{MeC}_{6} \mathrm{H}_{4}$ & $\mathrm{C}_{6} \mathrm{H}_{5}$ & 74 (3az) & $5 / 1$ & 96 \\
\hline 27 & Me & $\mathrm{C}_{6} \mathrm{H}_{5}$ & $\mathrm{Me}$ & 91 (3ba) & $>19 / 1$ & 98 \\
\hline 28 & $\mathrm{Me}$ & $m-\mathrm{MeC}_{6} \mathrm{H}_{4}$ & $\mathrm{Me}$ & 77 (3bb) & $>19 / 1$ & 98 \\
\hline 29 & $\mathrm{Me}$ & $p-\mathrm{MeOC}_{6} \mathrm{H}_{4}$ & Et & 80 (3bc) & $>19 / 1$ & 99 \\
\hline 30 & Me & $m-\mathrm{FC}_{6} \mathrm{H}_{4}$ & $p-\mathrm{MeC}_{6} \mathrm{H}_{4}$ & 76 (3bd) & 7/1 & 97 \\
\hline 31 & $\mathrm{Me}$ & 2-Naphthyl & $\mathrm{Bn}$ & 81 (3be) & $>19 / 1$ & 98 \\
\hline 32 & Et & $\mathrm{C}_{6} \mathrm{H}_{5}$ & $\mathrm{Me}$ & 88 (3bf) & $>19 / 1$ & $>99$ \\
\hline $33^{\#}$ & & $-\left(\mathrm{CH}_{2}\right)_{2^{-}}$ & $\mathrm{Me}$ & 76 (3bg) & $16 / 1$ & $>99$ \\
\hline $34^{\#}$ & & $-\left(\mathrm{CH}_{2}\right)_{2}^{-}$ & $\mathrm{C}_{6} \mathrm{H}_{5}$ & 51 (3bh) & $4 / 1$ & $>99$ \\
\hline 35 & & $-\left(\mathrm{CH}_{2}\right)_{3}^{-}$ & $\mathrm{C}_{6} \mathrm{H}_{5}$ & 95 (3bi) & $>19 / 1$ & $>99$ \\
\hline 36 & & $-\left(\mathrm{CH}_{2}\right)_{3}^{-}$ & Et & 97 (3bj) & $>19 / 1$ & $>99$ \\
\hline 37 & & $-\left(\mathrm{CH}_{2}\right)_{4}^{-}$ & $\mathrm{C}_{6} \mathrm{H}_{5}$ & 61 (3bk) & $19 / 1$ & 97 \\
\hline
\end{tabular}

*All reactions were carried out using the following reaction conditions: $\mathbf{2}$ (1.5 equiv., $0.30 \mathrm{mmol}$ ), $\alpha, \beta$-unsaturated ketone $\mathbf{1}(1.0$ equiv., $0.20 \mathrm{mmol}, 0.5 \mathrm{M})$, catalyst $\mathbf{1 0 d}(0.1$ equiv., $0.02 \mathrm{mmol})$ and 0 $\mathrm{NO}_{2}-\mathrm{C}_{6} \mathrm{H}_{4} \mathrm{CO}_{2} \mathrm{H}(0.2$ equiv., $0.04 \mathrm{mmol})$ in $\mathrm{CHCl}_{3}$ for $72 \mathrm{~h}$.

$\dagger$ Yield of the isolated product.
.

†ेDetermined by gas chromatography and confirmed by ${ }^{1} \mathrm{H}$-nuclear magnetic resonance of the crude reaction mixture.

§Determined by chiral high-performance liquid chromatography.

\#Reaction time: $120 \mathrm{~h}$.

absence of acidic additives would determine moderate yields with excellent enantio- and diastereoselectivities. Doubly alkyl-substituted butenolides gave similar results as those obtained with singly alkyl-substituted butenolides (Table 3, entry 9). With 5 -phenylfuran-2(3H)-one as the pro-nucleophile, reactions with enones bearing various short, long or branched chain alkyl groups afforded the corresponding syn-adducts in satisfactory yields with good enantioselectivities and moderate to high diastereoselectivities (from $1 / 10$ to $<1 / 19$ d.r.) (Table 4 , entries 10-17).
Different $\gamma$-substituted butenolides and enones paired together randomly as shown in Table 4 also gave good enantioselectivities and diastereoselectivities (from $1 / 15$ to $<1 / 19$ d.r.) (Table 4 , entries 18-22). Also, when $\mathrm{R}^{1}$ substituent was an ethyl group, the corresponding product was obtained in a moderate diastereoselectivity (1/9 d.r.) and yield but with a good enantioselectivity (Table 4 , entry 23).

We found that reaction of $\gamma$-phenyl-butenolide and the benzalacetone proceeded poorly in terms of enantioselectivity 
Table 4 | Scope of the Michael reaction for the syn-diastereoisomers 4.

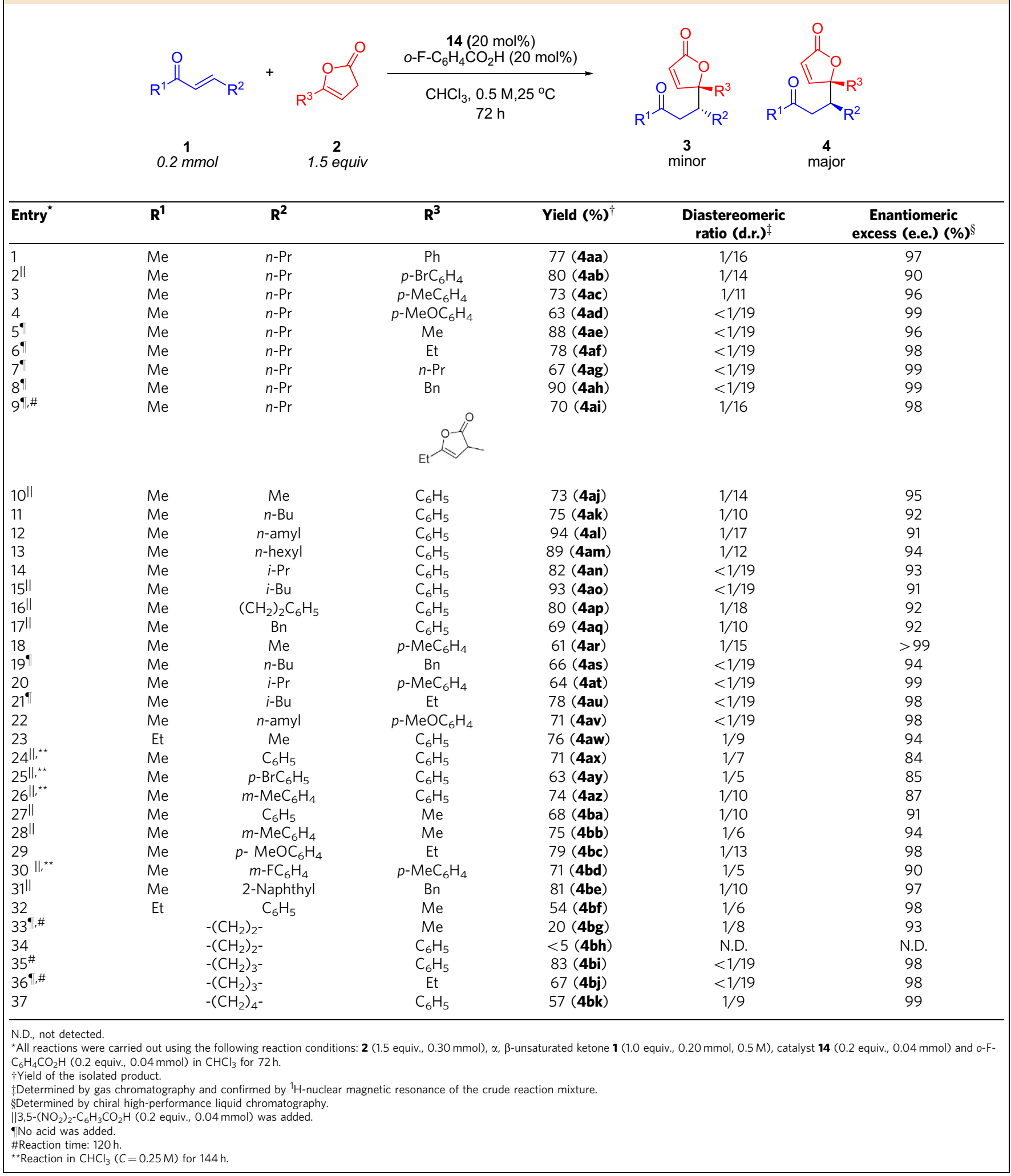

( $55 \%$ e.e.) and diastereoselectivity ( $1 / 2.7$ d.r.). However, by employing 3,5-dinitrobenzoic acid instead of 2-fluorobenzoic as the acidic additive in a more diluted reaction mixture (Supplementary Table 4), satisfactory yields with good enantioselectivities (84-90\% e.e.) and better diastereoselectivities (from 1/ 5 to $1 / 10$ d.r.) could be achieved (Table 4 , entries $24-26,30$ ). The reaction of $\gamma$-alkyl-butenolides and benzalacetone derivatives proceeded well, efficiently providing the syn-configured products in excellent enantioselectivities and moderate-to-good diastereoselectivities (from 1/6 to $1 / 13$ d.r.) (Table 4, entries 27-29, 31-32). The reaction of 2 -cyclopentenone (a challenging substrate) and $\alpha$-angelica lactone resulted in a good enantioselectivity and 
moderate diastereoselectivity, but a low yield that reflected poor conversion (20\% yield after $144 \mathrm{~h}$, Table 4 , entry 33 ). However, disappointingly, the reaction of 2-cyclopentenone and $\gamma$-phenylbutenolide showed only trace conversion (Table 4, entry 34 ). However, with 2-cyclohexenone as substrate, reactions with both $\alpha$-angelica lactone and $\gamma$-phenyl-butenolide afforded the corresponding syn-configured adducts in moderate yields with excellent enantio- and diastereoselectivities (Table 4, entries 35, 36). For the reaction of $\gamma$-phenyl-butenolide and the 2cyclopentenone, the corresponding adducts were obtained in moderate yields with excellent enantioselectivity and moderate diastereoselectivity (1/9 d.r.) (Table 4 , entry 37 ).

As shown in Table 4, our results demonstrate a broadly useful method for the synthesis of syn-configured adducts from a wide range of substrates using catalyst 14 .

Substrate scope of anti-selective Mukaiyama-Michael reaction. After fully establishing the scope of the Michael reaction for both anti- and syn-configured diastereoisomers, we wanted to further examine the possibility of applying the catalyst dual-control strategy in the Mukaiyama-Michael reaction, using $\gamma$-substituted$\mathrm{N}$-Boc-2-(tert-butyldimethylsilyl)oxy-pyrroles $\mathbf{1 6}$ as nucleophiles. After adjusting certain parameters (Supplementary Table 5), the optimal reaction conditions for the anti-selective MukaiyamaMichael reaction were established using catalyst 10c. As shown in Table 5, with $\gamma$-methyl-N-Boc-2-(tert-butyldimethylsilyl)oxypyrrole as one substrate, the reaction with various enones was successful and anti-configured products were obtained in moderate yields with good enantioselectivities and moderate diastereoselectivities (from 5/1 to 7/1 d.r.) (Table 5, entries 1-3). Using $\gamma$ phenyl- $N$-Boc-2-(tert-butyldimethylsilyl)oxy-pyrrole and benzalacetone as the substrates, an excellent enantioselectivity ( $96 \%$ e.e.) was observed albeit with a poor diastereoselectivity (1.2/1 d.r.) (Table 5, entry 4). In this Mukaiyama-Michael reaction, alcohol or $\mathrm{H}_{2} \mathrm{O}$ can accelerate the deprotection of TBS. However, fast deprotection will result in $\gamma$-substituted 3-pyrrolidin-2-one without Michael reaction.

Substrate scope of syn-selective Mukaiyama-Michael reaction. After certain parameters had been adjusted and the optimal reaction conditions for the complementary syn-selective Mukaiyama-Michael reaction established using catalyst 14, the same substrate scope of $\gamma$-substituted-N-Boc-2-(tert- butyldimethylsilyl)oxy-pyrroles 16 and $\alpha, \beta$-unsaturated ketones was probed. As summarized in Table 6, the corresponding adducts were obtained in moderate-to-good yields with good enantio- and diastereoselectivities (from $1 / 11$ to $1 / 16$ d.r.) (Table 6, entries 1-3). Using $\gamma$-phenyl- $N$-Boc-2-(tert-butyldimethylsilyl)oxy-pyrrole and benzalacetone as the substrates, a poor diastereoselectivity (1/1.2 d.r.) was again observed; however, the major anti-configured product was formed with good enantioselectivity (Table 6, entry 4 ). These results demonstrated that our non-enantiomeric catalyst-controlled strategy for diastereodivergence could be applied to the Mukaiyama-Michael reaction of $\gamma$-substituted- $N$-Boc-2-(tert-butyldimethylsilyl) oxy-pyrrole 16 to $\alpha, \beta$-unsaturated ketones.

Diastereodivergent tandem Michael-Michael reactions. The feasibility of a catalyst-controlled diastereodivergent process in the tandem Michael-Michael reaction also attracted our attention. As demonstrated in Fig. 2, 5-phenylfuran-2(3H)-one was reacted with enone 19 (possessing a suitably placed hydroxyl group) under the control of catalyst 10d and subsequently treated with $\mathrm{Et}_{3} \mathrm{~N}$ for another $12 \mathrm{~h}$. Diastereoisomer 20 was obtained in a good yield (83\%) with excellent enantioselectivity and no other diastereoisomer was detected in the reaction mixture. However, under the control of catalyst $\mathbf{1 4}$ the corresponding diastereoisomer, product $\mathbf{2 1}$, was obtained directly and efficiently $(76 \%$ yield) and with excellent enantioselectivities ( $94 \%$ e.e.) using optimal reaction conditions established above. The relative stereochemical configurations of both products 20 and 21 were established using single-crystal X-ray analysis (Supplementary Tables 6 and 7).

Derivatization of the adducts. Having successfully extended diastereodivergent processes to a variety of reaction types and a wide range of substrates, we then devoted our efforts to exploring some additional transformations of the enantioenriched and diastereomerically pure Michael addition products, as demonstrated in Fig. 3. Interestingly, the anti-adduct $\mathbf{3 a b}$ was transformed, presumably via a 1,3-dipolar cycloaddition, into an unprecedented $[5,5,5]$ tricyclic cage-like compound 22 as a single diastereoisomer when treated with thiosemicarbazide and heated in $\mathrm{AcOH}$ at $110^{\circ} \mathrm{C}$ overnight. A single crystal of product 22 was subjected to X-ray analysis and established the configuration of $3 \mathbf{a b}$ to be $R, R$ (Supplementary Table 8). Interestingly, the syn-adduct 4aa performed differently under the same

Table 5 | Scope of the anti-selective Mukaiyama-Michael reaction.

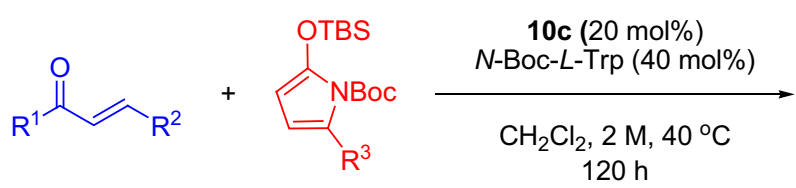

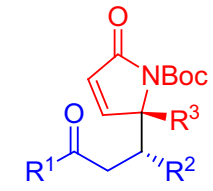

17

major<smiles>[R]C(=O)CC([R])C1([R])C=CC(=O)N1C(=O)O</smiles>

18

minor

\begin{tabular}{lcccccc}
\hline Entry $^{\star}$ & $\mathbf{R}^{\mathbf{1}}$ & $\mathbf{R}^{\mathbf{2}}$ & $\mathbf{R}^{\mathbf{3}}$ & Yield (\%) $^{\dagger}$ & Diastereomeric ratio (d.r.) $^{\ddagger}$ & Enantiomeric excess (e.e.) (\%) $^{\S}$ \\
\hline 1 & $\mathrm{Me}$ & $\mathrm{Ph}$ & $\mathrm{Me}$ & $75(\mathbf{1 7 a})$ & $5 / 1$ & 98 \\
2 & $\mathrm{Me}$ & $m-\mathrm{MeC}_{6} \mathrm{H}_{4}$ & $\mathrm{Me}$ & $56(\mathbf{1 7 b})$ & $5 / 1$ & 94 \\
3 & $\mathrm{Me}$ & $n-\mathrm{Pr}$ & $\mathrm{Me}$ & $64(\mathbf{1 7 c})$ & $7 / 1$ & 96 \\
4 & $\mathrm{Me}$ & $\mathrm{Ph}$ & $\mathrm{Ph}$ & $38(\mathbf{1 7 d})$ & $1.2 / 1$ & 96
\end{tabular}

Enantiomeric excess (e.e.) (\%)

${ }^{*}$ All reactions were carried out using the following reaction conditions: $\mathbf{2}$ ( 3.0 equiv., $\left.0.60 \mathrm{mmol}\right), \alpha, \beta$-unsaturated ketone $\mathbf{1}$ (1.0 equiv., $0.20 \mathrm{mmol}, 2 \mathrm{M}$ ), catalyst $10 \mathrm{c}(0.2 \mathrm{equiv}$, $0.04 \mathrm{mmol})$ and $\mathrm{N}$-BocL-Trp $(0.40$ equiv., $0.08 \mathrm{mmol})$ at $40^{\circ} \mathrm{C}$ in $\mathrm{CH}_{2} \mathrm{Cl}_{2}$ for $120 \mathrm{~h}$

$\uparrow$ Yield of the isolated product.

$\ddagger$ Determined by ${ }^{1} \mathrm{H}$-nuclear magnetic resonance of the crude reaction mixture.

$\S$ Determined by chiral high-performance liquid chromatography. 
Table 6 | Scope of the syn-selective Mukaiyama-Michael reaction.

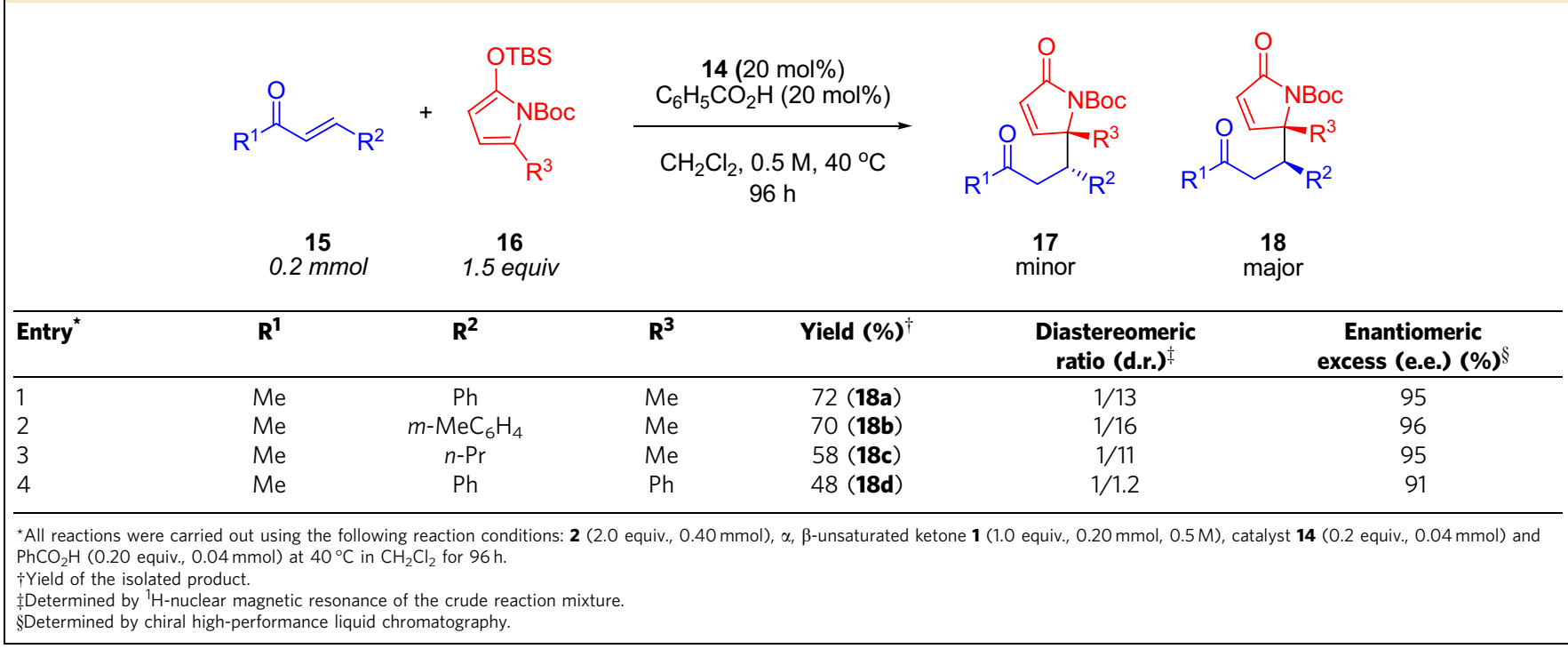

a<smiles>CC(=O)/C=C/c1ccccc1O</smiles><smiles>O=C1CC=C(Pc2ccccc2)O1</smiles>
$\underset{\mathrm{o}-\mathrm{NO}_{2}-\mathrm{C}_{6} \mathrm{H}_{4} \mathrm{CO}_{2} \mathrm{H}(20 \mathrm{~mol} \%)}{\stackrel{\mathrm{CHCl}_{3}, 0.5 \mathrm{M},}{2}} \stackrel{\frac{0.5 \text { equiv. } \mathrm{Et}_{3} \mathrm{~N}}{12 \mathrm{~h}}}{\underset{25}{\circ} \mathrm{C}, 3 \mathrm{~d}}$<smiles>CC(=O)C[C@H]1c2ccccc2O[C@H]2CC(=O)O[C@]21c1ccccc1</smiles>

19
$0.2 \mathrm{mmol}$

$2 \mathrm{a}$

$0.2 \mathrm{mmol} \quad 1.5$ equiv.

20 Yield $83 \%$ e.e. $96 \%$

b<smiles>CC(=O)/C=C/c1ccccc1O</smiles>
$0.2 \mathrm{mmol}$ 1.5 equiv.

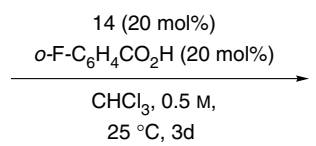

$25^{\circ} \mathrm{C}, 3 \mathrm{~d}$

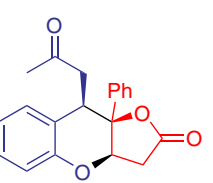

21 Yield $76 \%$ e.e. $94 \%$

Figure 2 | Catalyst-controlled enantioselective diastereodivergent tandem Michael-Michael reactions. (a) Catalyzed by catalyst 10d, (b) catalyzed by catalyst 14.

a<smiles>CC(=O)CC(CC(C)C)C1(c2ccc(Br)cc2)C=CC(=O)O1</smiles>

$3 a b$

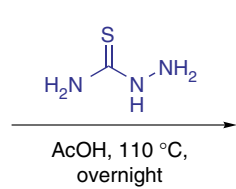

b<smiles>CCPC(CC(C)=O)C1(c2ccccc2)C=CC(=O)O1</smiles>
4 aa

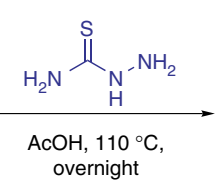
overnight

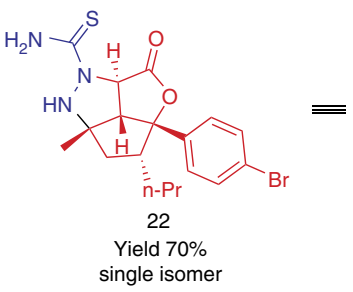

single isome

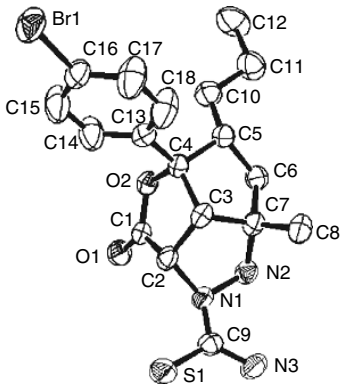

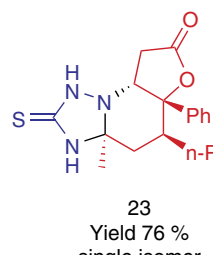

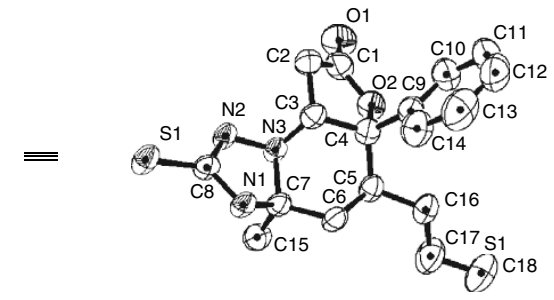

Figure 3 | Derivatization of the Michael addition products. (a) 1,3-Dipolar cycloaddition of adduct 3ab. (b) Tandem reaction of $\mathbf{4 a a .}$ 
conditions and was transformed into a complex-fused ring compound 23 via a combination of an aza-Michael addition reaction and an aminoacetalization. Single-crystal X-ray analysis of product $\mathbf{2 3}$ established the configuration of $\mathbf{4 a a}$ to be $R, S$ (Supplementary Table 9).

\section{Discussion}

In short, we have established new methodologies to control the selective formation of remote stereocenters at $\gamma$-positions via diastereodivergent catalytic asymmetric processes. We have developed two catalytic systems and investigated their applicability in the asymmetric vinylogous Michael addition of $\gamma$-substituted butenolides to $\alpha, \beta$-unsaturated ketones. The reactions proceed smoothly with a wide range of substrates and afforded selectively either syn- or anti-configured products, possessing vicinal quaternary and tertiary stereogenic centres, with high enantiocontrol.

Furthermore, this approach was applicable to the MukaiyamaMichael addition of $\gamma$-substituted- $N$-Boc-2-(tert-butyldimethylsilyl) oxy-pyrrole 16 to $\alpha, \beta$-unsaturated ketones and also tandem reactions of $\gamma$-substituted butenolides with $\alpha, \beta$-unsaturated ketone 21. Both catalytic systems could access major diastereomers with high enantiocontrol but minor diastereomers with low or moderate enantiocontrol. In addition, the different configurations of Michael adducts were diversified further to structure-divergent complex heterocyclic compounds. Studies on further applications of the reported strategy are currently underway and will be reported in due course.

\section{Methods}

General methods. For high-performance liquid chromatography charts, ${ }^{1} \mathrm{H}$ and ${ }^{13} \mathrm{C}$ nuclear magnetic resonance spectra of compounds in this manuscript, see Supplementary Figs 1-253. Single-crystal X-ray analysis of catalyst 10c and 14, see Supplementary Tables 10 and 11. For details of the synthetic procedures, see Supplementary Methods.

\section{References}

1. Carreira, E. M. \& Kvaerno, L. Classics in Stereoselective Synthesis (Wiley, 2009).

2. Blaser, H. U. \& Schmidt, E. Asymmetric Catalysis on Industrial Scale (Wiley, 2004).

3. Oliveira, M. T., Luparia, M., Audisio, D. \& Maulide, N. Dual catalysis becomes diastereodivergent. Angew. Chem. Int. Ed. 52, 13149-13152 (2013).

4. Huang, Y., Walji, A. M., Larsen, C. H. \& MacMillan, D. W. C. Enantioselective organo-cascade catalysis. J. Am. Chem. Soc. 127, 15051-15053 (2005).

5. Wang, Y., Liu, X. \& Deng, L. Dual-function cinchona alkaloid catalysis: catalytic asymmetric tandem conjugate addition-protonation for the direct creation of nonadjacent stereocenters. J. Am. Chem. Soc. 128, 3928-3940 (2006).

6. Wang, B., Wu, F., Wang, Y., Liu, X. \& Deng, L. Control of diastereoselectivity in tandem asymmetric reactions generating nonadjacent stereocenters with bifunctional catalysis by cinchona alkaloids. J. Am. Chem. Soc. 129, 768-769 (2007).

7. Tian, X. et al. Diastereodivergent asymmetric sulfa-Michael additions of $\alpha$-branched enones using a single chiral organic catalyst. J. Am. Chem. Soc. 133, 17934-17941 (2011)

8. Luparia, M. et al. Catalytic asymmetric diastereodivergent deracemization. Angew. Chem. Int. Ed. 50, 12631-12635 (2011).

9. Audisio, D., Luparia, M., Oliveira, M. T., Klütt, D. \& Maulide, N. Diastereodivergent de-epimerization in catalytic asymmetric allylic alkylation. Angew. Chem. Int. Ed. 51, 7314-7317 (2012).

10. Krautwald, S., Sarlah, D., Schafroth, M. A. \& Carreira, E. M. Enantio- and diastereodivergent dual catalysis: $\alpha$-allylation of branched aldehydes. Science 340, 1065-1068 (2013).

11. Krautwald, S., Schafroth, M. A., Sarlah, D. \& Carreira, E. M. Stereodivergent $\alpha$-allylation of linear aldehydes with dual iridium and amine catalysis. J. Am. Chem. Soc. 136, 3020-3023 (2014).

12. Clayden, J. Transmission of stereochemical information over nanometre distances in chemical reactions. Chem. Soc. Rev. 38, 817-829 (2009)

13. Christoffers, J. \& Baro, A. Quaternary Stereocenters (Wiley, 2005).

14. Rodŕguez, A. D. The natural products chemistry of west indian gorgonian octocorals. Tetrahedron 51, 4571-4618 (1995).

15. Mann, A. \& Christoffers, J. Enantioselective construction of quaternary stereocenters. Angew. Chem. Int. Ed. 40, 4591-4597 (2001).

16. Rao, Y. S. Recent advances in the chemistry of unsaturated lactones. Chem. Rev. 76, 625-694 (1976).
17. Alali, F. Q., Liu, X.-X. \& McLaughlin, J. L. Annonaceous acetogenins: recent progress. J. Nat. Prod. 62, 504-540 (1999).

18. Shiomi, K. et al. A $\gamma$-lactone form nafuredin, nafuredin- $\gamma$, also inhibits helminth complex I. J. Antibiot. 58, 50-55 (2005).

19. Cui, H.-L. et al. Direct asymmetric allylic alkylation of butenolides with MoritaBaylis-Hillman carbonates. Org. Lett. 12, 720-723 (2010).

20. Quintard, A., Lefranc, A. \& Alexakis, A. Highly enantioselective direct vinylogous Michael addition of $\gamma$-butenolide to enals. Org. Lett. 13, 1540-1543 (2011).

21. Zhou, L. et al. Catalytic asymmetric vinylogous Mannich-type (AVM) reaction of nonactivated $\gamma$-angelica lactone. Org. Lett. 13, 3056-3059 (2011).

22. Huang, X., Peng, J., Dong, L. \& Chen, Y.-C. Asymmetric assembly of 2-oxindole and $\alpha$-angelica lactone units to construct vicinal quaternary chiral centers. Chem. Commun. 48, 2439-2441 (2012).

23. Manna, M. S. \& Mukherjee, S. Catalytic asymmetric direct vinylogous Michael addition of deconjugated butenolides to maleimides for the construction of quaternary stereogenic centers. Chem. Eur. J. 18, 15277-15282 (2012).

24. Zhang, W. et al. Highly enantio- and diastereoselective reactions of $\gamma$ substituted butenolides through direct vinylogous conjugate additions. Angew. Chem. Int. Ed. 51, 10069-10073 (2012).

25. Manna, M. S., Kumar, V. \& Mukherjee, S. Catalytic enantioselective construction of quaternary stereocenters by direct vinylogous Michael addition of deconjugated butenolides tonitro olefins. Chem. Commun. 48, 5193-5195 (2012).

26. Das, U., Chen, Y.-R., Tsai, Y.-L. \& Lin, W. Organocatalytic enantioselective direct vinylogous Michael addition of $\gamma$-substituted butenolides to 3-aroyl acrylates and 1, 2-diaroylethylenes. Chem. Eur. J. 19, 7713-7717 (2013).

27. Huang, H. et al. Asymmetric vinylogous Michael reaction of $\alpha, \beta$-unsaturated ketones with $\gamma$-butenolide under multifunctional catalysis. Chem. Commun. 46, 5957-5959 (2010).

28. Huang, H., Jin, Z., Zhu, K., Liang, X. \& Ye, J. Highly diastereo- and enantioselective synthesis of 5-substituted 3-pyrrolidin-2-ones through a direct vinylogous michael addition under multifunctional catalysis. Angew. Chem. Int Ed. 50, 3232-3235 (2011).

29. Li, P., Wang, Y., Liang, X. \& Ye, J. Asymmetric multifunctional organocatalytic Michael addition of nitroalkanes to $\alpha, \beta$-unsaturated ketones. Chem. Commun. 3302-3304 (2008).

30. Yu, F., Hu, H., Gu, X. \& Ye, J. Asymmetric Michael addition of substituted rhodanines to $\alpha, \beta$-unsaturated ketones catalyzed by bulky primary amines. Org. Lett. 14, 2038-2041 (2012).

\section{Acknowledgements}

This work was partially supported by National Natural Science Foundation of China (21272068), Program for New Century Excellent Talents in University (NCET-13-0800) Innovation Program of Shanghai Municipal Education Commission (11ZZ56), the 111 Project (Grant B07023) and the Fundamental Research Funds for the Central Universities and the EPSRC (Leadership Fellowship to D.J.D.).

\section{Author contributions}

X.L. principally performed the experiments and wrote the manuscript, M.L., Y.D., W.W. and Q.Q. performed the experiments, J.Y. conceptualized and directed the research and wrote the manuscript, D.J.D. conceptualized and wrote the manuscript, all authors discussed the results and commented on the manuscript.

\section{Additional information}

Accession codes: The X-ray crystallographic coordinates for structures reported in this Article have been deposited at the Cambridge Crystallographic Data Centre (CCDC), under deposition numbers CCDC-981120 (cat. 10c), CCDC-981119 (cat. 14), CCDC996776 (20), CCDC-996772 (21), CCDC-981117 (22) and CCDC-981118 (23). These data can be obtained free of charge from The Cambridge Crystallographic Data Centre via www.ccdc.cam.ac.uk/data_request/cif.

Supplementary Information accompanies this paper at http://www.nature.com/ naturecommunications

Competing financial interests: The authors declare no competing financial interests.

Reprints and permission information is available online at http://npg.nature.com/ reprintsandpermissions/

How to cite this article: Li, X. et al. Diastereodivergent organocatalytic asymmetric vinylogous Michael reactions. Nat. Commun. 5:4479 doi: 10.1038/ncomms5479 (2014).

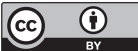

This work is licensed under a Creative Commons Attribution 4.0 International License. The images or other third party material in this article are included in the article's Creative Commons license, unless indicated otherwise in the credit line; if the material is not included under the Creative Commons license, users will need to obtain permission from the license holder to reproduce the material. To view a copy of this license, visit http://creativecommons.org/licenses/by/4.0/ 